\title{
Utilization of Agro-Waste in the Elimination of Dyes from Aqueous Solution: Equilibrium, Kinetic and Thermodynamic Studies
}

\section{Nnaemeka J. Okorocha ${ }^{1, a^{*}}$, Chijioke E. Omaliko, ${ }^{2, b}$, Collins C. Osuagwu ${ }^{3, c}$ Chijioke-Okere O. Maureen ${ }^{4, d}$ Conrad K. Enenebeaku ${ }^{5, e}$}

\author{
${ }^{1,2}$ Department of Pure and Industrial Chemistry, University of Calabar, Nigeria) \\ ${ }^{3}$ Department of Chemical Engineering, Imo State Polytechnic Umuagwo, Nigeria \\ ${ }^{4,5}$ Department of Chemistry, Federal University of Technology Owerri, Nigeria) \\ aemybeck@yahoo.com, bchijiokeomaliko@unical.edu.ng, 'cmosion22@yahoo.com, \\ doby.chijioke85@gmail.com, eenecon92002@yahoo.com
}

Keywords: Adsorption, Congo red, Isotherms, Kinetics, Maize cob powder, Malachite green

\begin{abstract}
The prospective of maize cob powder (MCP) as an effective adsorbent for the removal of malachite green (MG) and congo red (CR) dyes from aqueous solution was investigated. The presence of functional groups and pores on maize cob powder were confirmed by FTIR and SEM analysis. Batch adsorption studies were conducted and various parameters such as contact time, adsorbent dosage, initial dye concentration, $\mathrm{pH}$ and temperature were examined to observe their effects in the dyes adsorption process. The optimum conditions for the adsorption of MG and CR onto the adsorbent (MCP) was found to be: contact time (60mins), $\mathrm{pH}$ (10.0) and temperature (303 $\mathrm{K}$ ), adsorbent dose $(1 \mathrm{~g})$ for an initial $\mathrm{MG}$ dye concentration of $50 \mathrm{mg} / \mathrm{L}$ and contact time (80mins), $\mathrm{pH}(2.0)$ and temperature $(343 \mathrm{~K})$ for an initial CR dye concentration of $50 \mathrm{mg} / \mathrm{L}$ and adsorbent dose $1.0 \mathrm{~g}$ respectively. The experimental equilibrium adsorption data fitted best and well to the Freundlich isotherm model for CR dye adsorption and Langmuir Isotherm for MG adsorption. The maximum adsorption capacity was found to be $13.02 \mathrm{mg} / \mathrm{g}$ and $9.41 \mathrm{mg} / \mathrm{g}$ for the adsorption of MG and CR dyes respectively. The kinetic data conformed to the pseudo-second-order kinetic model. Thermodynamic quantities such as Gibbs free energy $\left(\Delta \mathrm{G}^{0}\right)$, enthalpy $\left(\Delta \mathrm{H}^{0}\right)$ and entropy $\left(\Delta \mathrm{S}^{0}\right)$ were evaluated and the negative values of $\Delta \mathrm{G}^{0}, \Delta \mathrm{H}^{0}$ and $\Delta \mathrm{S}^{0}$ obtained indicated the spontaneous and exothermic nature of the MG adsorption process while positive enthalpy $\left(\Delta \mathrm{H}^{0}\right)$ indicated an endothermic nature of $\mathrm{CR}$ adsorption process.
\end{abstract}

\section{Introduction}

Our earth is the only planet in the whole universe accredited with life in abundance. One of the principal factors, which support life in our mother-planet, is water. But, anthropogenic activities have caused a great harm to the quality of our lifeline, i.e. water. Because of rapid exhaustion of the freshwater resources, there exists some crisis [1]. Colour is considered as the first pollutant to be identified in waste water and it is mostly caused by effluents discharged form dyeing industries such as paper, rubber, leather, cosmetics, textile, pharmaceuticals, plastics and food industries [2]. This discharged coloured (dye) effluent can seriously hinder the penetration of light and disturb the biological processes occurring in many water bodies. More so, the natural degradation of these dye compounds, when released into the environment, usually yields highly toxic and carcinogenic products [3-5].

Malachite green (Basic green) is an N-methylateddiaminotriphenylmethane dye most widely used for colouring purpose among all other dyes of its category [6]. It is an extensively used biocide in the aquaculture industry worldwide. It is also used as a food colouring agent, food additive, a medical disinfectant as well as a dye in silk, wool, cotton, paper, etc industries [7-8]. However there are several reports describing its carcinogenic and hazardous effects [9]. Congo red (CR) is a benzidine-based anionic bisazo dye known to metabolize to benzidine, a known human carcinogen 
[10]. Congo red (CR) is toxic to animals and plants and thus its introduction to water stream is of potential health, environmental, and ecological concern [11].

Removal of these dyestuffs from wastewater using various physio-chemical and biological techniques such as filtration, precipitation, coagulation, aerobic and anaerobic decolouration, ozone treatment etc. are all complex and expensive techniques which limits their commercial application. Adsorption appears to be one of the best techniques because of its simplicity of design and cost effectiveness [12-13].

The use of activated carbon is, by far, one of the oldest and most employed adsorbents for the removal of many dyes from solutions because of its high surface area and porous nature [14]. However, the continuous use of commercially available activated carbon is limited by its high cost. This has led researchers into studying the efficacy of relatively cheaper and readily available unconventional adsorbents obtained from plant materials to function as effective adsorbents for dyes elimination [15-18].

Maize is largely produced in Africa especially Nigeria and its cobs are left in the environment during processing and after consumption. The availability of corn cobs as waste material is vast in Nigeria. The objective of this study is to investigate the possibility of maize cob powder as an alternative adsorbent in removing of Malachite green and Congo red dyes from aqueous solution. Characterizations of maize cob powder were done by SEM and FTIR analysis. The influence of contact time, adsorbent dose, initial dye concentration, $\mathrm{pH}$ and temperature were evaluated. Adsorption isotherms, kinetics, mechanism and thermodynamic parameters were also evaluated and reported.

\section{Literature Review}

Raw corn cob was investigated as potential adsorbents for the removal of methylene blue, MB dye by Enenebeaku, Okorocha and Akalezi [19] via batch method. Optimum conditions for the various adsorption parameters examined showed contact time (30 mins), $\mathrm{pH}(10.0)$ and temperature (343 K) for an initial $\mathrm{MB}$ dye concentration of $100 \mathrm{mg} / \mathrm{L}$ and adsorbent dose $1.0 \mathrm{~g}$. It was seen that as the amount of adsorbent increased, the percentage of dye removal increased consequently. The experimental equilibrium adsorption data fitted best to the Freundlich and Halsey isotherm models, while the kinetic data conformed to the pseudo-second-order kinetic model. The maximum adsorption capacity was found to be $18.28 \mathrm{mg} / \mathrm{g}$. Okorocha et al. [20] investigated the adsorption of $\mathrm{Pb}^{2+}$ and $\mathrm{Cu}^{2+}$ ions by raw corn cobs. Adsorption increases with increasing adsorbent dosage for the two metal ions. Pseudo-second order kinetic model provided an appropriate representation of the metal ions adsorption, while the experimental equilibrium adsorption data fitted best to Langmuir isotherm model.

The removal of Malachite green (MG) from aqueous solution was examined by Malik et al. [21] using groundnut shell, an agricultural solid waste as an adsorbent. The experimental results indicated that at a dose of $0.5 \mathrm{~g} / \mathrm{L}$ and initial concentration of $100 \mathrm{mg} / \mathrm{L}$, groundnut shell powder activated carbon showed $94.5 \%$ removal of the dye in 30 minutes equilibrium time, while commercially available powdered activated carbon removed $96 \%$ of the dye in 15 minutes. The equilibrium data fitted best to the Freundlich isotherm model. The Adsorption of Congo red (CR) dye from aqueous solution using dried roots of Eichhornia crassipes was studied by Wanyonyi et al. [22]. Batch experiments were carried out for adsorption kinetics and isotherms. Experimental results obtained showed that adsorption process was highly reliant on contact time, adsorbent dosage, initial dye concentration and particle size. The adsorption equilibrium for Congo red dye by E. crassipes (roots) was reached within 90 minutes and adsorption efficiency of $96 \%$ was achieved. The adsorption kinetics followed a pseudo-second-order kinetic model while Freundlich isotherm model was best applicable for obtaining the equilibrium parameters. 


\section{Experimental}

\section{Preparation of MCP adsorbent}

The maize cobs were obtained from Ihiagwa market and its environs in Owerri west local government area of Imo state, Nigeria. The collected cobs were severally washed with tap water and double distilled water, cut into small pieces thereafter, stored at $50^{\circ} \mathrm{C}$ until moisture content was stably insignificant. The dried maize cob were then crushed, sieved to pass through $150 \mu \mathrm{m}$ mesh size, collected into air-tight containers and kept in air-tight desiccators to be used as adsorbent and labelled MCP.

\section{Preparation of dye solution}

Stock solution of malachite green and congo red dyes solution were prepared by dissolving $1 \mathrm{~g}$ of each commercially available dye (Fluka grade) in $1 \mathrm{~L}$ of distilled water to obtain a stock concentration of $1000 \mathrm{mg} / \mathrm{L}$. Experimental dye solutions of desired concentrations were prepared by appropriate dilution of stock solution.

\section{Batch Adsorption Studies}

Batch adsorption experiments were conducted to investigate the effects of contact time, adsorbent dose, initial concentration, $\mathrm{pH}$ and temperature for $\mathrm{MG}$ and $\mathrm{CR}$ adsorption on the adsorbent (MCP) with solutions of different initial concentration of MG and CR ranging from $25 \mathrm{mg} / \mathrm{L}$ to $130 \mathrm{mg} / \mathrm{L}$. The adsorbents dose of $1.0 \mathrm{~g}$ was added to $100 \mathrm{ml}$ of $50 \mathrm{mg} / \mathrm{L}$ dye solutions. The temperature was controlled at $27^{\circ} \mathrm{C}$. The series of conical flasks were shaken on a rotary shaker at a constant speed of $100 \mathrm{rpm}$. Samples were withdrawn for spectrophotometer analysis at predetermined duration of contact time ranging from 10 to 120 minutes. The equilibrium dye concentrations (Ce) were then measured and the amount of dyes adsorbed per unit weight of the adsorbents at equilibrium (qe) were determined by

$\mathrm{q}_{\mathrm{e}}=\left(\mathrm{C}_{0}-\mathrm{C}_{\mathrm{e}}\right) \frac{\mathrm{V}}{\mathrm{W}}$

Where $\mathrm{W}$ is the mass of adsorbent $(\mathrm{g}), \mathrm{V}$ is the volume of solution $(\mathrm{L}), \mathrm{C}_{\mathrm{o}}$ is the initial concentration of dye $(\mathrm{mg} / \mathrm{L}), \mathrm{C}_{\mathrm{e}}$ is the equilibrium dye concentration $(\mathrm{mg} / \mathrm{L})$ and $\mathrm{q}_{\mathrm{e}}$ is the amount of dye adsorbed at equilibrium $(\mathrm{mg} / \mathrm{g})$.

Dye removal $(\%)=\frac{\mathrm{C}_{0}-\mathrm{C}_{\mathrm{e}}}{\mathrm{C}_{0}} \times 100$

Where $\mathrm{C}_{0}$ and $\mathrm{C}_{\mathrm{e}}$ are initial and equilibrium (final) dye concentrations, respectively.

\section{Results and Discussion}

\section{Effect of Contact time}

The plot for the variation of the percentage removal of MG and CR dyes at different contact times is provided in Fig. 1. It was observed that the sorption of MG and CR dyes by MCP was rapid at the first 20 minutes and increased slowly in the later stages until optimum adsorption (equilibrium time) at 60 minutes and 80 minutes for MG and CR dyes respectively. Nevertheless, the percentage removal of the dyes sharply dropped slightly after equilibrium time. The result shows that increasing contact time favours the prolonged interaction between the MG and CR dye molecules and the MCP surface and subsequent permeation into the adsorbent pores until saturation is attained at 60 and 80 minutes respectively. Nevertheless, the sharp loss of adsorbed MG and CR dye molecules, with contact time beyond their respective equilibrium times ( $60 \& 80$ mins) indicates that the dislodged dye molecules were weakly held during saturation. This is feasible for the 
formation a secondary adsorption layer (held with weak bond) on a primarily adsorbed dye layer (having stronger attachment with the MCP substrate) [23].

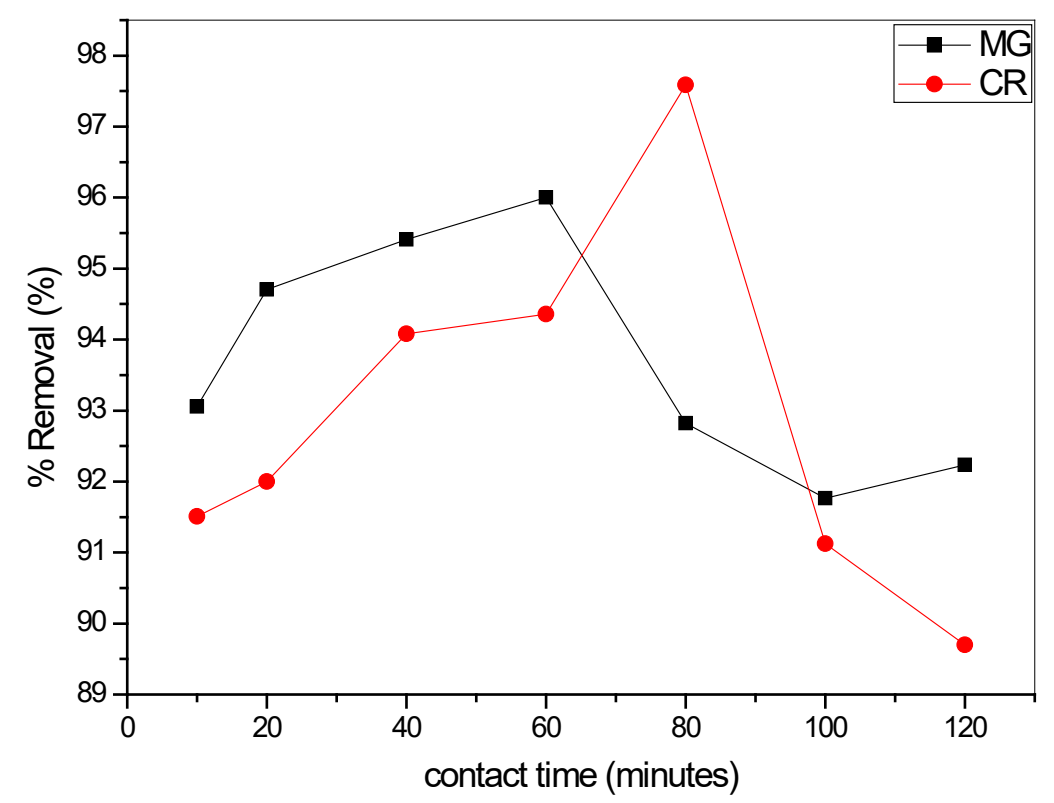

Fig. 1: Effect of contact time on the percentage removal of MG and CR dyes onto MCP

\section{Effect of Adsorbent Dosage}

The variation plot for the effect of adsorbent dosage on the percentage removal MG and CR dyes onto MCP is provided in Fig. 2. The percentage removal of MG and CR dyes increased from $81.88 \%$ to $98.12 \%$ and from $83.51 \%$ to $97.48 \%$ respectively indicating increase in removal efficiency of the dyes with increase in adsorbent dosage. This observation can be attributed to the fact that the number of active sites on MCP surface increased with the increase in the dosage of MCP which led to increase in the MG and CR dyes removal [24].

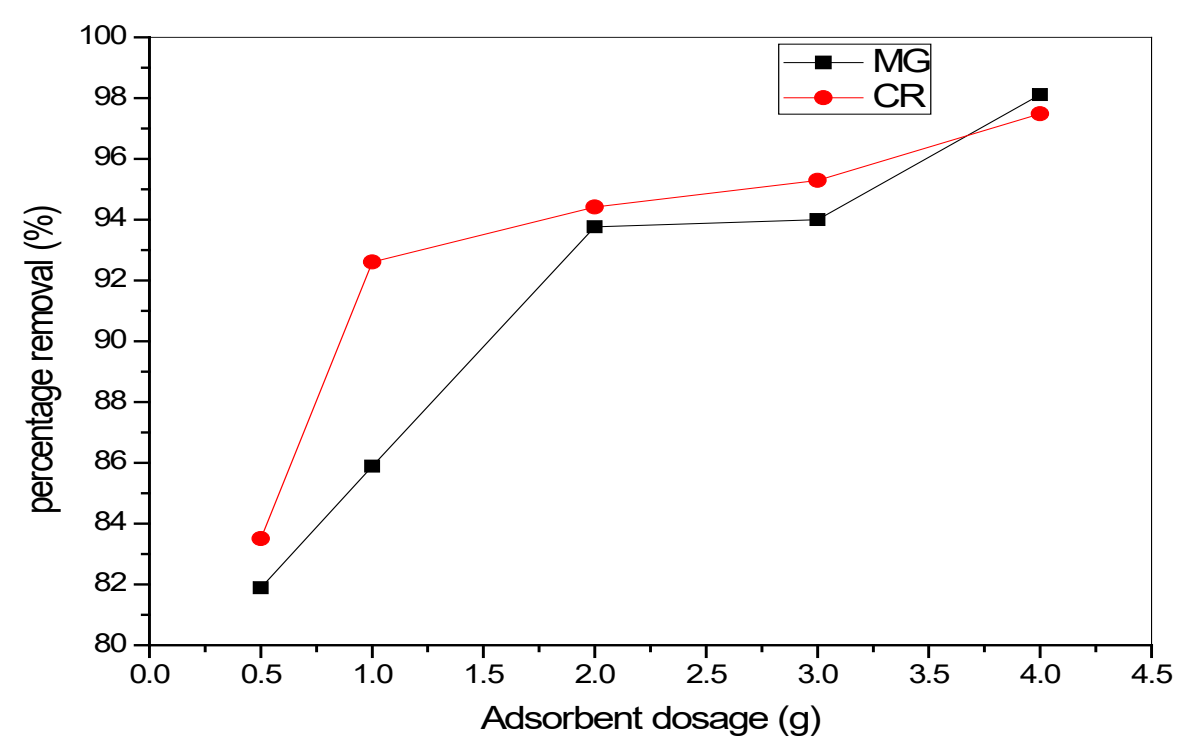

Fig. 2: Effect of adsorbent dosage on the percentage removal of MG and CR dyes onto MCP

\section{Effect of Initial dyes Concentration}

The variation of amount of MG and CR dyes adsorbed, qe, for different initial dye concentration in the presence of $1 \mathrm{~g} \mathrm{MCP}$ adsorbent and after 60 and 80 minutes contact time respectively at $27^{\circ} \mathrm{C}$. 
The result obviously shows that the qe value for $\mathrm{MG}$ and CR steadily increased from $2.34 \mathrm{mg} / \mathrm{g}$ to $10.58 \mathrm{mg} / \mathrm{g}$ and from 2.14 to $11.47 \mathrm{mg} / \mathrm{g}$ respectively in the presence of $25 \mathrm{mg} / \mathrm{L}$ to $130 \mathrm{mg} / \mathrm{L}$ of the dyes. Such trend has also been reported for the adsorption of many dyes on several other adsorbents $[25,26]$. This can be understood from the fact that increasing the initial dye concentration for a fixed adsorbent dose promotes a concentration gradient that continuously overcomes the resistance to the mass transfer of the dye from solution to the MCP surface. Thus, the adsorption of MG and $\mathrm{CR}$ dyes and subsequent permeation into the pores of the adsorbent, are both facilitated with increasing dye concentration.

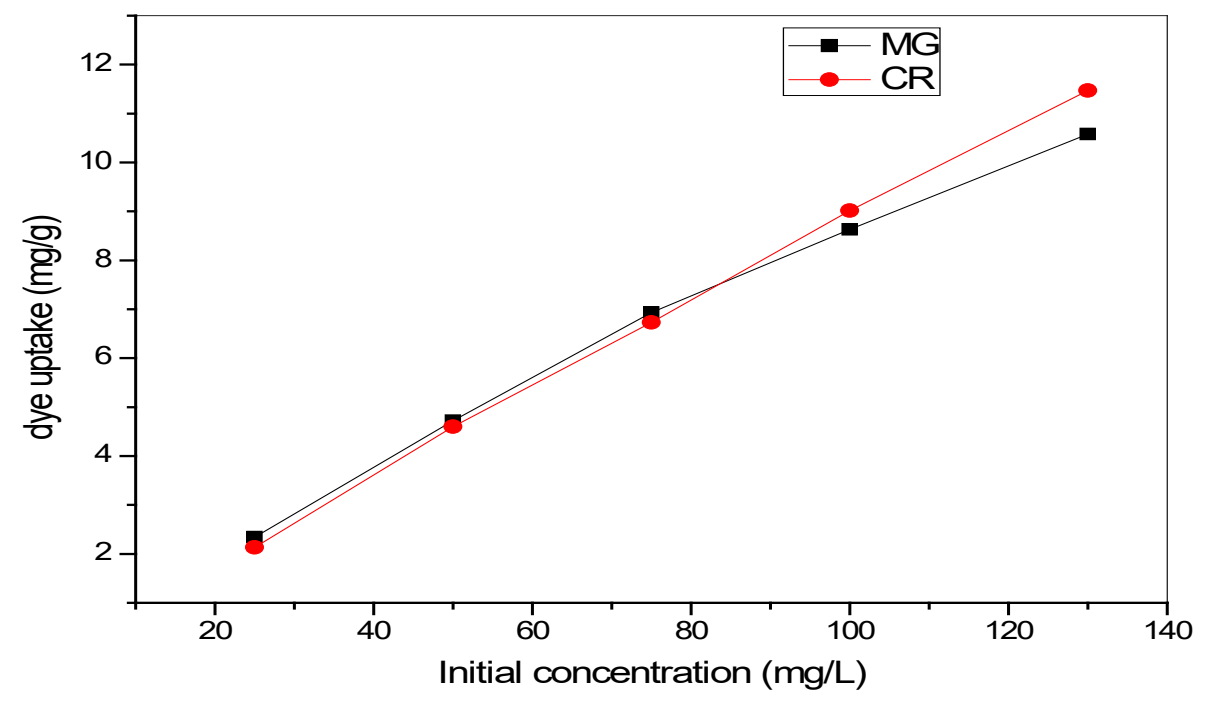

Fig. 3: Effect of Initial Concentration on the amount of MG and CR dyes adsorbed onto MCP

\section{Effect of pH}

It can be observed from Fig. 4 that the percentage removal of MG dyes by MCP increased from $91.06 \%$ to $97.76 \%$ respectively with increase in $\mathrm{pH}$ from 2 to 10 . Optimum sorption was obtained at $\mathrm{pH}$ of 10 . The increase in percentage removal and adsorption capacity with increase in $\mathrm{pH}$ can be attributed to the fact that at low $\mathrm{pH}$ values of the solution, the presence of excess hydrogen ion in the solution competes with the cationic groups of the MG dye for the adsorption sites on the adsorbent surface. While at high $\mathrm{pH}$ values, the positive charges $\left(\mathrm{H}^{+}\right)$at the solution interphase decreases and the adsorbent surface is more negatively charged, thus enhancing attraction of more amounts of the cations of the MG dye [27].

The adsorption capacity and percentage removal of CR dyes by MCP decreased from $99.45 \%$ to $88.66 \%$ respectively as $\mathrm{pH}$ increased from 2 to 10 . Optimum sorption was obtained at $\mathrm{pH}$ of 2 . The decrease in percentage removal and adsorption capacity with increase in $\mathrm{pH}$ can be attributed to the fact that at high $\mathrm{pH}$ values of the solution, the presence of excess hydroxyl ion in the solution competes with the anionic groups of the CR dye for the adsorption sites on the adsorbent surface. While at low $\mathrm{pH}$ values, the negative charges in the solution decreases and the adsorbent surface is more positively charged, thus enhancing attraction of more amounts of the anions of the CR dye [28]. 


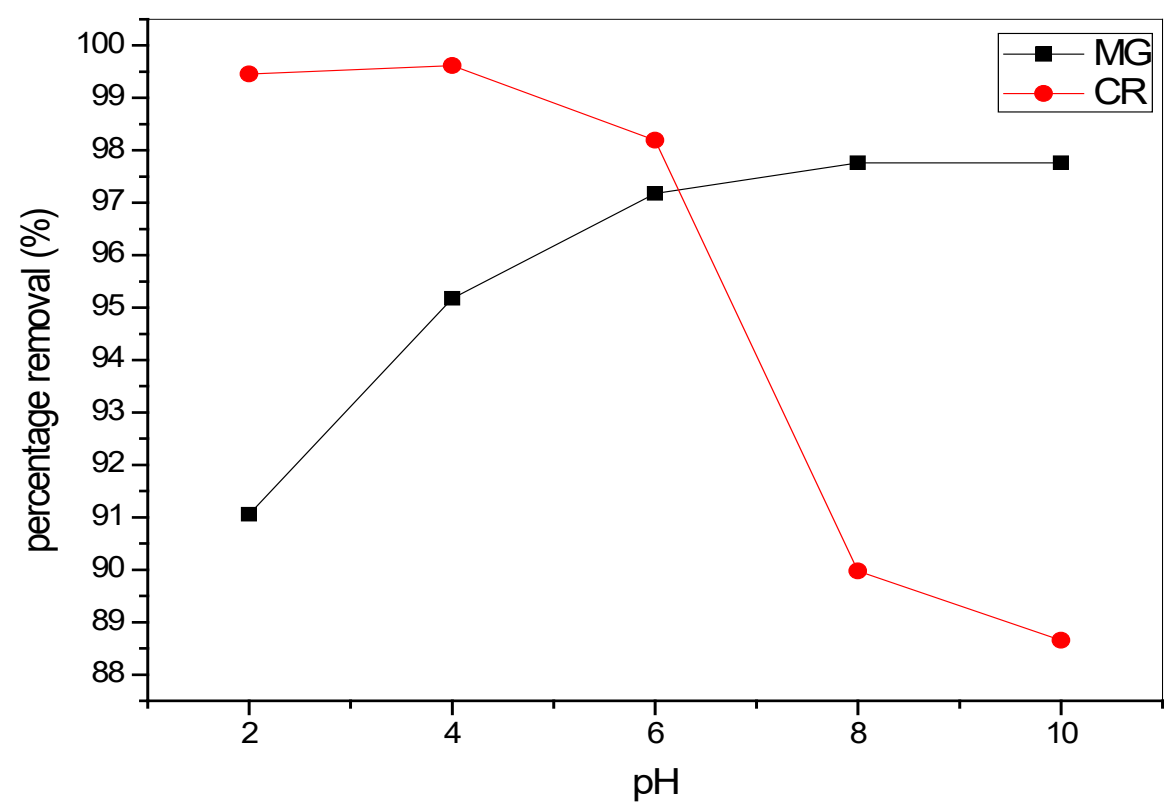

Fig. 4: Effect of $\mathrm{pH}$ on the adsorption of $\mathrm{MG}$ and $\mathrm{CR}$ dyes onto $\mathrm{MCP}$

\section{Effect of Temperature}

The influence of temperature on the removal of efficiency of MG and CR dyes by MCP is illustrated in Fig. 5. The percentage removal decreased from $95.88 \%$ to $85.18 \%$ for $\mathrm{MG}$ onto MCP. While it increased from $84.82 \%$ to $99.4 \%$ for CR onto MCP as temperature increased from 30 to $70^{\circ} \mathrm{C}$. The decrease in adsorption efficiency with increase in temperature for MG onto MCP can be attributed mainly to the fact that as the temperature increases, the physical bonding between the MG dye and the active sites of MCP weakened. In addition, the MG solubility also increased which caused the interaction between the MG molecules and solvent to become stronger than that between MG and MCP adsorbent. Therefore, MG dye became more difficult to adsorb [29]. While the increase in adsorption efficiency with increase in temperature for CR onto MCP can be attributed to increase in both the mobility of the CR dye molecules and the number of active sites for the adsorption; hence the adsorption is an endothermic process [30].

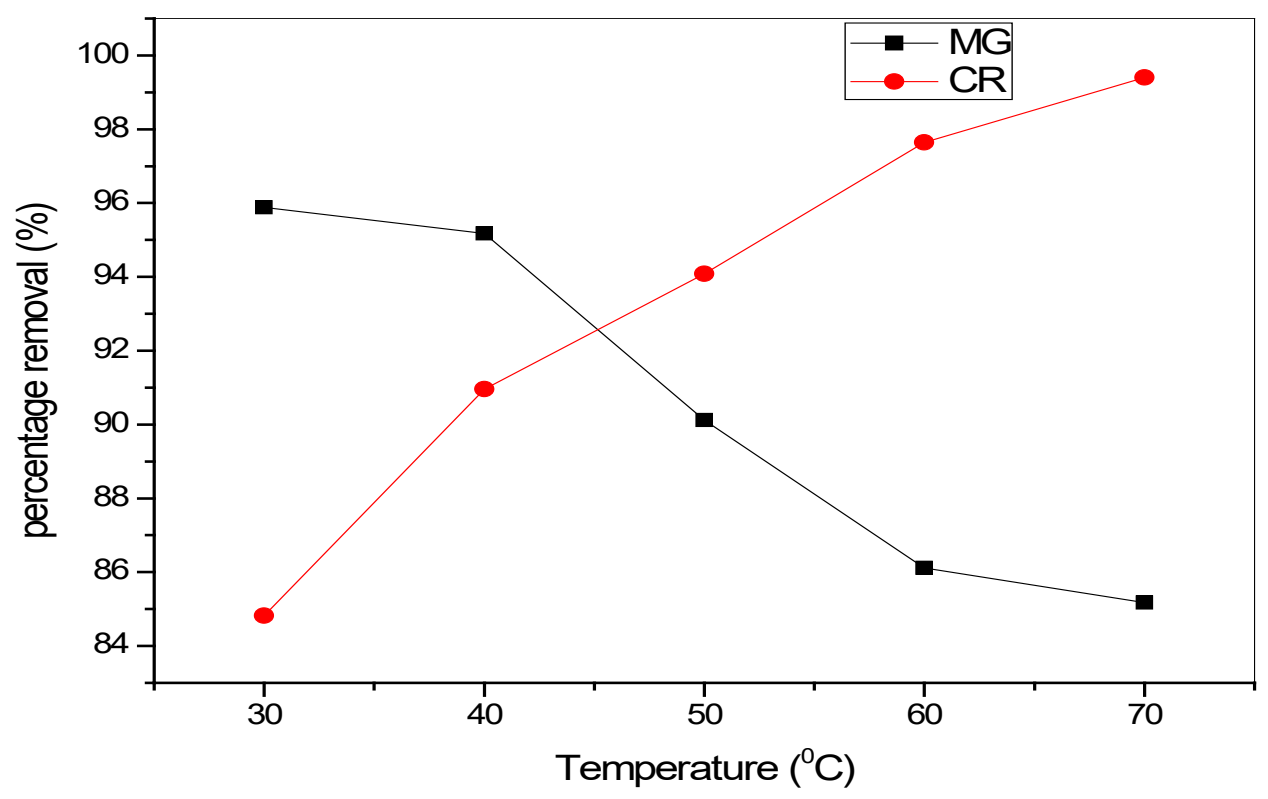

Fig. 5: Effect of temperature on the adsorption of MG and CR dyes onto MCP 


\section{Adsorption Isotherms}

To comprehend the nature of the interaction involving the elimination of $\mathrm{MG}$ and $\mathrm{CR}$ dyes by effect of the MCP adsorbent, the experimental data was analyzed according to the linear form of the Langmuir and Freundlich isotherm models. The Langmuir isotherm can be represented by the following equation:

$\frac{C_{e}}{q_{e}}=\frac{1}{q_{m} K_{l}}+\frac{C_{e}}{q_{m}}$

Where $q_{e}(\mathrm{mg} / \mathrm{g})$ is the amount of dye adsorbed at equilibrium, $q_{m}(\mathrm{mg} / \mathrm{g})$, the amount of dye adsorbed when saturation is attained, $C_{e}$ is the equilibrium dye concentration $(\mathrm{mg} / \mathrm{L})$ and $K_{l}$ is Langmuir constant related to the binding strength of dye onto the adsorbent.

The linearized form of Freundlich equation is expressed as

$\log q_{e}=\log K_{f}+\frac{1}{n} \log C_{e}$

Where $K_{f}$ and $n$ are the Freundlich constants that represent adsorption capacity and intensity (strength) of adsorption respectively.

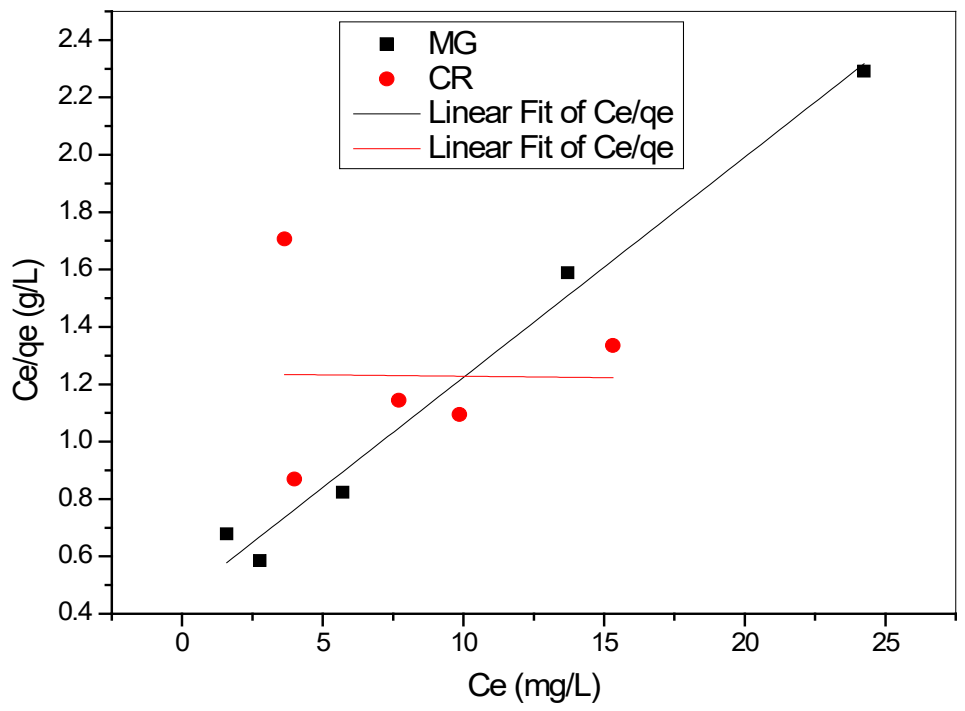

Fig. 6: Langmuir isotherm plot for adsorption of $M G$ and $C R$ onto $M C P$ 


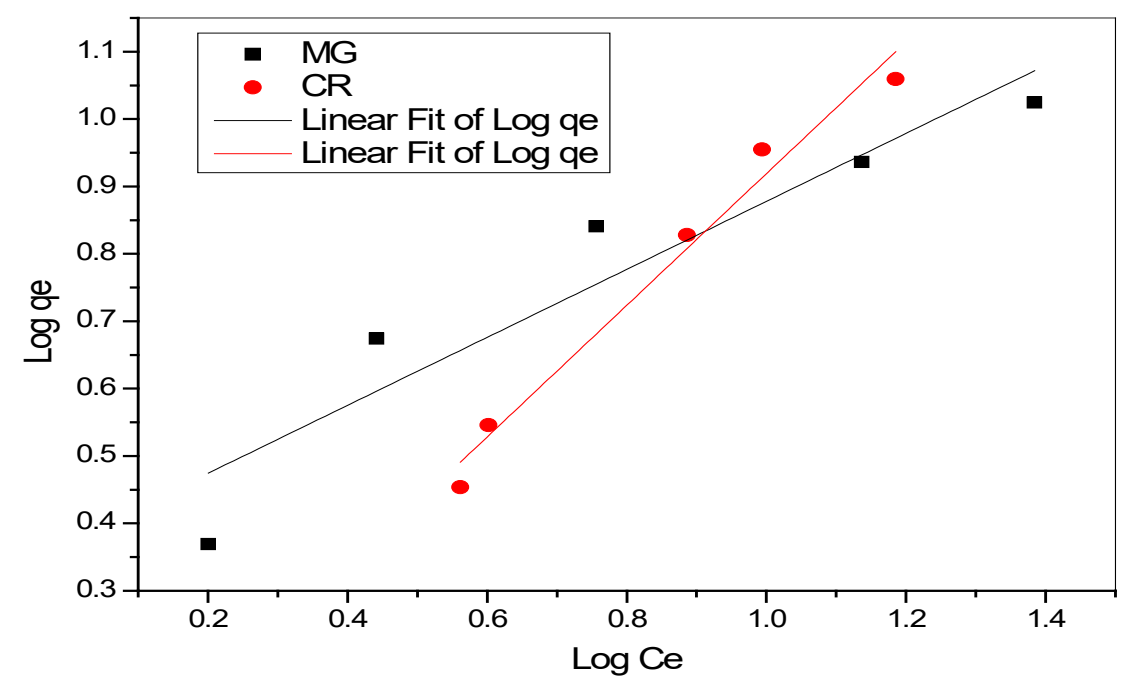

Fig. 7: Freundlich isotherm plot for adsorption of MG and CR onto MCP

Figure 6 and 7 show the Langmuir and Freundlich model plot for the adsorption of MG and CR dyes onto MCP respectively. The isotherm parameters and $\mathrm{R}^{2}$ values are summarized in Table 1 . It is evident from the plot in (Fig. 6) and the values of correlation coefficient $\left(\mathrm{R}^{2}\right.$ ) (Table 1) that the Langmuir plot was adequate in describing the adsorption process of MG onto MCP, but was inadequate in describing the adsorption of CR onto MCP. Hence such MG adsorption occurred mainly on the homogenous surfaces of MCP. Figure 7 further evidence the adequacy of Freundlich model to describe the adsorption of CR onto MCP. Hence such CR adsorptions mainly occurred on the heterogeneous surface of MCP.

Table 1: Isotherm Parameters and values of correlation coefficient for MG and $\mathrm{CR}$ adsorption

\begin{tabular}{|l|l|l|l|l|l|l|}
\hline \multicolumn{3}{|c|}{ Langmuir Isotherm Model } & \multicolumn{2}{l|}{ Freundlich Model } \\
\hline Dyes & $\begin{array}{l}\text { Qmax } \\
(\mathbf{m g} / g)\end{array}$ & $K_{\mathbf{L}}$ & $\mathbf{R}^{\mathbf{2}}$ & $\mathbf{n}$ & $\mathbf{K}_{\mathbf{F}}(\mathbf{m g} / \mathbf{g})(\mathbf{L} / \mathbf{m g})^{\mathbf{1 / n}}$ & $\mathbf{R}^{\mathbf{2}}$ \\
\hline MG & 13.02 & 0.168 & 0.982 & 1.98 & 2.363 & 0.866 \\
CR & -1037.7 & 0.001 & 0.333 & 1.02 & 9.41 & 0.973 \\
\hline
\end{tabular}

\section{Adsorption kinetics}

The pseudo-first-order and pseudo-second-order kinetic models were applied to study the adsorption kinetics. The pseudo-first-order rate constant $\left(\mathrm{k}_{1}\right)$ and $\mathrm{q}_{\mathrm{e}}$ determined from the model are presented in Table 2. It was observed that the relationship between the dye solution diffusivity, $\ln \left(\mathrm{q}_{\mathrm{e}}\right.$ $-\mathrm{q}_{\mathrm{t}}$ ) against $\mathrm{t}$ was non-linear (figure not shown). It is also observed that the calculated $\mathrm{q}_{\mathrm{e}}$ values did not agree with the experimental $\mathrm{q}_{\mathrm{e}}$ since the calculated $\mathrm{q}_{\mathrm{e}}$ values were neither equal nor reasonably close to the experimental $\mathrm{q}_{\mathrm{e}}$ values (Table 2). Therefore, pseudo-first-order model was inadequate in representing the adsorption of $\mathrm{MG}$ and $\mathrm{CR}$ onto MCP.

Furthermore, Figure 8 shows the pseudo-second-order kinetic models plot for the adsorption of MG and CR onto MCP. The pseudo-second-order rate constant $\mathrm{k}_{2}$, and $\mathrm{q}_{\mathrm{e}}$ determined from the model are presented in Table 2. It was observed from Table 4.18 that there are good agreement between the calculated $\mathrm{q}_{\mathrm{e}}$ values and the experimental $\mathrm{q}_{\mathrm{e}}$ values i.e. $\mathrm{q}_{\mathrm{e}}$ (cal.) and $\mathrm{q}_{\mathrm{e}}$ (exp.) for the adsorption of 
MG and CR by MCP. In addition, highly linear plots with high values of correlation coefficient were also observed from Fig.8 for the adsorption of MG and CR dyes by MCP. It is therefore evident that Pseudo-second-order is the best fit kinetic model in describing the adsorption processes. Similar results were obtained by other researchers [31, 32].

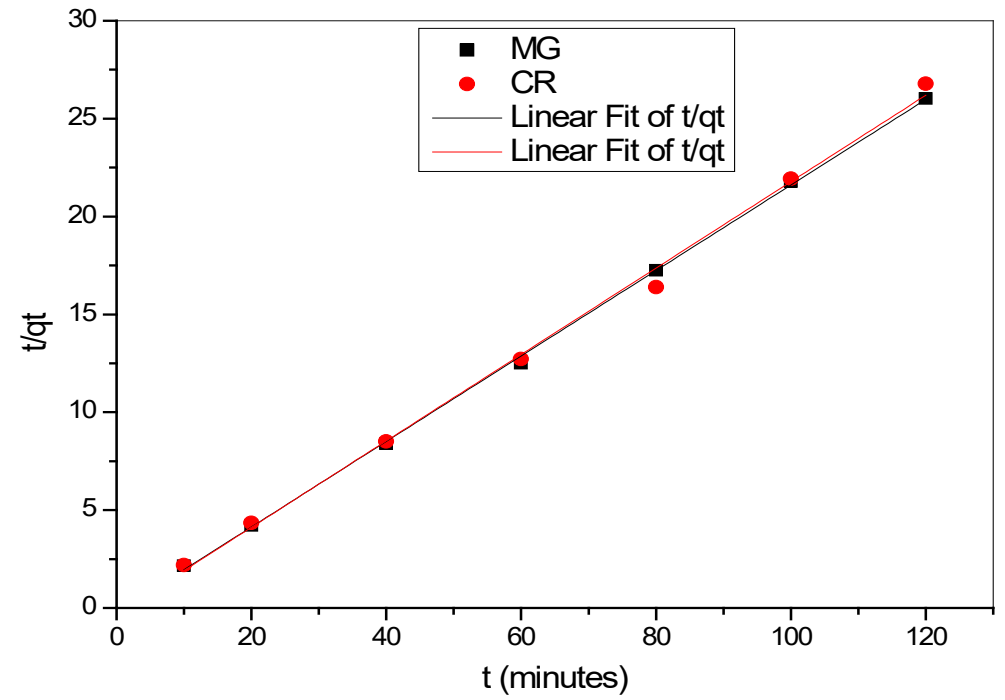

Fig.8: Pseudo second order plot for adsorption of MG and CR onto MCP

Table 2: Pseudo-first and second order kinetic model parameters for MG and CR onto MCP

\begin{tabular}{|c|c|c|c|c|c|c|c|c|}
\hline \multirow[b]{2}{*}{ Dyes } & \multicolumn{4}{|c|}{ Pseudo-First Order Model } & \multicolumn{4}{|c|}{ Pseudo-Second Order Model } \\
\hline & $\begin{array}{l}q_{e}(\exp ) \\
(\mathrm{mg} / \mathrm{g})\end{array}$ & $\begin{array}{l}\mathrm{k}_{1} \\
\left(\mathrm{~g} \cdot \mathrm{mg}^{-1} \mathrm{~min}^{-1}\right)\end{array}$ & $\begin{array}{l}q_{e}(\text { cal }) \\
(\mathrm{mg} / \mathrm{g})\end{array}$ & $\mathbf{R}^{2}$ & 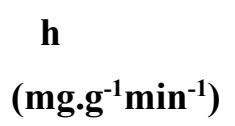 & $\begin{array}{l}\mathrm{K}_{2} \\
\left(\mathrm{~g} \cdot \mathrm{mg}^{-1} \mathrm{~min}^{-1}\right)\end{array}$ & $\begin{array}{l}q_{\mathrm{e}}(\mathrm{cal}) \\
(\mathrm{mg} / \mathrm{g})\end{array}$ & $\mathbf{R}^{2}$ \\
\hline MG & 4.81 & 0.0094 & 0.043 & 0.062 & 4.440 & 0.2117 & 4.58 & 0.999 \\
\hline $\mathrm{CR}$ & 4.89 & 0.0031 & 0.086 & 0.189 & 3.411 & 0.1662 & 4.53 & 0.996 \\
\hline
\end{tabular}

\section{Adsorption Thermodynamics}

The thermodynamic parameters such as change in Gibb's free energy $\left(\Delta G^{0}\right)$, change in enthalpy $\left(\Delta \mathrm{H}^{0}\right)$ and change in entropy $\left(\Delta \mathrm{S}^{0}\right)$ for the adsorption of the dyes onto MCP have been determined using the following equations:

The Gibb's free energy, $\Delta \mathrm{G}$, equation is expressed as follows:

$\Delta G=-R T \ln K_{a d s}$

The equilibrium constants (Kads) were calculated according to the following equation:

$$
K_{a d s}=\frac{\text { Dye concentration on the solid (adsorbent)at equilibrium }\left(q_{e}^{m}\right)}{\text { Dye concentration in solution at equilibrium }\left(C_{e}\right)}
$$

The Van't Hoff equation is expressed as follows:

$\ln K_{a d s}=\frac{\Delta S^{0}}{R}-\frac{\Delta H^{0}}{R T}$ 
Where $R$ is gas constant, $T$ is absolute temperature in Kelvin, $\Delta S$ and $\Delta H^{0}$ are entropy and enthalpy respectively. The plot of $\ln K_{a d s}$ versus $1 / T$ gives a linear relationship, which allows the computation of $\Delta H$ and $\Delta S$ values from the slope and intercept respectively.

Table 3: Thermodynamic data for MG dye onto MCP

\begin{tabular}{|c|l|l|l|l|l|}
\hline $\mathbf{T}(\mathbf{K})$ & $\mathbf{k}_{\mathbf{c}}$ & $\mathbf{l n} \mathbf{k}_{\mathbf{c}}$ & $\boldsymbol{\Delta G}(\mathbf{K J} / \mathbf{m o l})$ & $\Delta \mathbf{H}(\mathbf{K J} / \mathbf{m o l} . \mathbf{K})$ & $\Delta \mathbf{S}(\mathbf{J} / \mathbf{m o l})$ \\
\hline 303 & 23.28571 & 3.14784 & -7929 & & \\
313 & 19.73171 & 2.982227 & -7760 & -32.888 & -82.14 \\
323 & 9.119048 & 2.210365 & -5935 & & \\
333 & 6.20339 & 1.825096 & -5052 & & \\
343 & 5.746032 & 1.748509 & -4986. & & \\
\hline
\end{tabular}

Table 4: Thermodynamic data for CR dye onto MCP

\begin{tabular}{|c|c|c|c|c|c|}
\hline $\mathbf{T}(\mathrm{K})$ & $\mathbf{k}_{\mathbf{c}}$ & $\ln \mathbf{k}_{\mathbf{c}}$ & $\Delta G(\mathrm{KJ} / \mathrm{mol})$ & $\Delta H(\mathrm{KJ} / \mathrm{mol} . \mathrm{K})$ & $\Delta \mathrm{S}(\mathrm{J} / \mathrm{mol})$ \\
\hline 303 & 5.588448 & 1.720702 & -4334 & \multirow{5}{*}{68.051} & \multirow{5}{*}{236.94} \\
\hline 313 & 10.06061 & 2.308627 & -6007 & & \\
\hline 323 & 15.89815 & 2.766203 & -7428 & & \\
\hline 333 & 41.44186 & 3.724291 & -1031 & & \\
\hline 343 & 164.9091 & 5.105394 & -1455 & & \\
\hline
\end{tabular}

Negative $\Delta G^{0}$ values obtained at all temperatures (Table $3 \& 4$ ) indicate the feasibility and the spontaneous nature of MG and CR dyes adsorption onto MCP.

The negative $\Delta H^{0}$ value confirms the exothermic nature of the adsorption of MG onto MCP. While the positive value of $\Delta H^{0}$ indicates the endothermic nature of CR adsorption onto MCP.

The negative value of $\Delta S^{0}$ reveals decreased randomness at the solid/solution interfaces and suggests the adsorption MG dye adsorption onto MCP was enthalpy driven [33]. While the positive value of $\Delta S$ suggest increased randomness at the solid/solution interphase for the adsorption of $\mathrm{CR}$ onto MCP [34].

\section{Adsorbent Characterization}

The FTIR spectral of maize cobs powder, MCP were obtained using $\mathrm{KBr}$ pellets within the spectral range of 4000-500 cm-1 and as shown in Fig. 9. The peaks at $526.58 \mathrm{~cm}^{-1}$ represent the carbon halogen $(\mathrm{C}-\mathrm{X})$ bond. Peaks at 1039.67 and $1190.12 \mathrm{~cm}^{-1}$ are due to $\mathrm{C}-\mathrm{O}$ stretch from alcohol and C$\mathrm{N}$ from aliphatic amine. Peaks at $1511.28 \mathrm{~cm}^{-1}$ show $\mathrm{N}-\mathrm{O}$ symmetric from nitro compounds. $\mathrm{C}=\mathrm{C}$ stretch is responsible for the peak at $1654.01 \mathrm{~cm}^{-1}$. Sharp peaks at $2265.47 \mathrm{~cm}^{-1}$ represents $\mathrm{C} \equiv \mathrm{C}$ stretch from alkyne. $\mathrm{C} \mathrm{N}$ stretch from nitriles is responsible for the peak at $2376.38 \mathrm{~cm}^{-1}$. The peaks at $3257.88 \mathrm{~cm}^{-1}, 3529.85 \mathrm{~cm}^{-1}$ and $3742.03 \mathrm{~cm}^{-1}$ are due to $\mathrm{O}-\mathrm{H}$ stretching (from alcohols and carboxylic acids) and N-H symmetric and asymmetric stretch from amines and amides respectively. $\mathrm{O}-\mathrm{H}$ from adsorbed water on the surface is responsible for the peak as $3857.76 \mathrm{~cm}^{-1}$.

Furthermore, Fig. 10 shows the SEM images of maize cob powder. It can be observed from 2500 magnifications that MCP surface shows very irregular surfaces with ridges. On further magnification (10000) as indicated the surface shows presence of pores. 


\section{FTIR- 8400S FOURIER TRANSFORM INFRARED SPECTROPHOTOMETER}

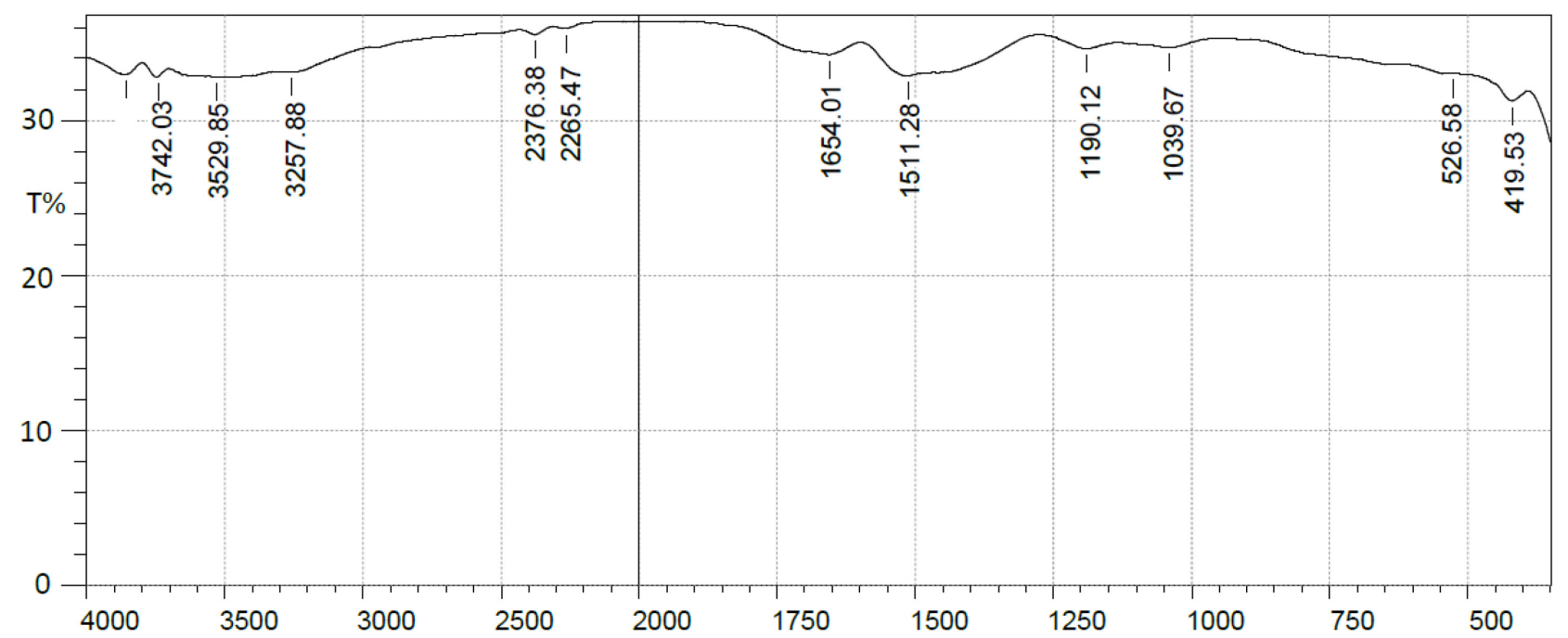

Fig. 9: FTIR spectra of maize cob powder (MCP)
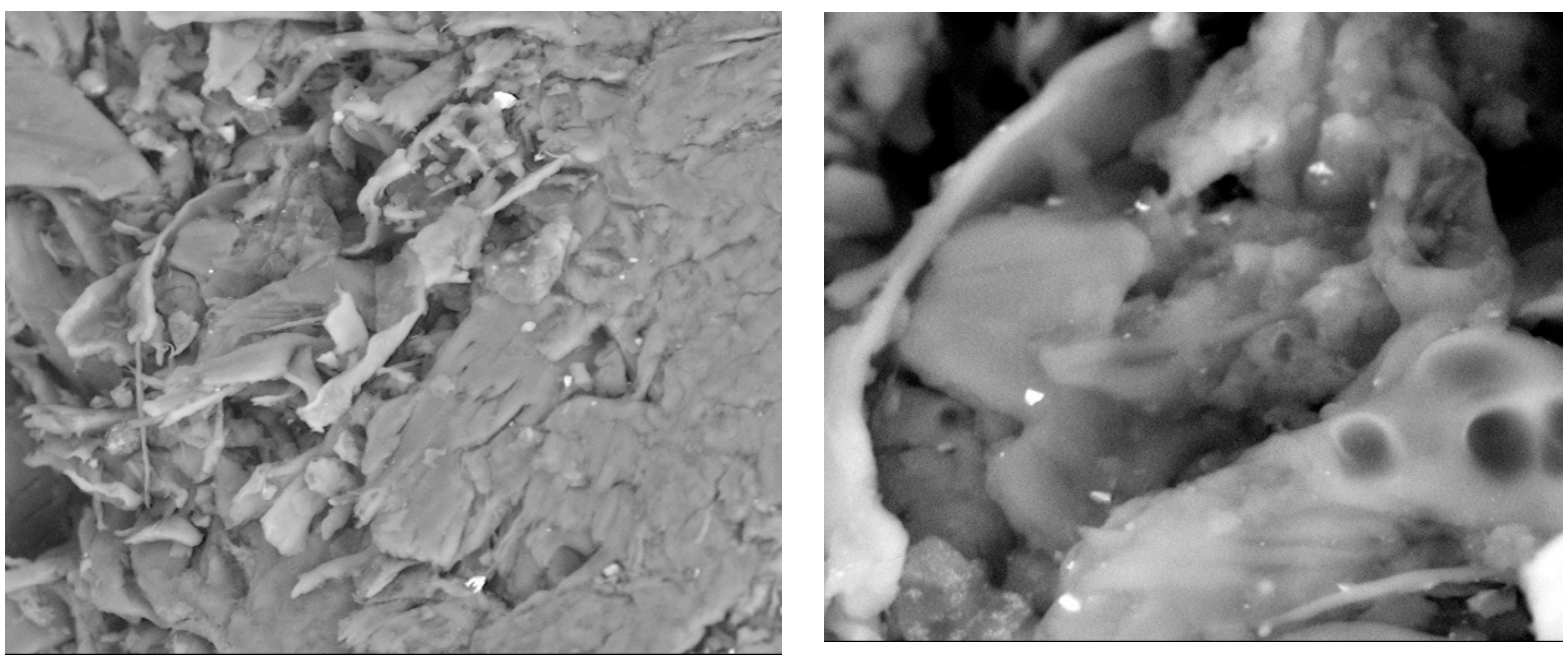

Fig 10: SEM images of maize cob powder at 2500x \& 10000x respectively

\section{Conclusion}

The adsorption of MG and CR dyes onto MCP powder was found to be influenced by contact time, adsorbent dose, initial concentration, temperature and initial $\mathrm{pH}$ of the solution. The optimum adsorption of MG and CR dyes was found at $\mathrm{pH} 10$ and 2 respectively. Temperature had strong influence on the adsorption processes. The kinetic studies revealed that the adsorption of MG and $\mathrm{CR}$ dyes onto CPP followed the pseudo-second-order kinetic model. The study on equilibrium sorption revealed that Langmuir isotherm model gave the best fit for MG adsorption while Freundlich isotherm model gave the best fit to the experimental data of CR adsorption onto the MCP adsorbent. The calculated thermodynamic parameters indicated a spontaneous and exothermic nature of the adsorption of MG dyes and endothermic nature for adsorption of CR dyes onto maize cobs powder. We conclude that maize cob powder MCP, can be effectively used as an inexpensive and efficient adsorbent without any pre-treatment or modification for the removal of Malachite green and Congo red dyes from aqueous solutions and effluents. 


\section{References}

[1] A. Hashem, R.A. Akasha, A. Ghith, D.A. Hussein, Adsorbent based on agricultural wastes for heavy metal and dye removal: A review, Energy Educ. Sci. Technol. 19 (2007) 69-86.

[2] T. Robinson, G. McMullan, R. Marchant, P. Nigam, Remediation of dyes in textile effluent: a critical review on current treatment technologies with a propose alternative, J. Biores. Tech. 77 (2001) 247-2752.

[3] S.K. Bajpai, A. Jain, Equilibrium and thermodynamic studies for adsorption of crystal violet onto spent tea leaves, Water. 4 (2012) 52-71.

[4] Y.S. Ho, Removal of copper ions from aqueous solution by free fern, Water Res., 37 (2003) 2323-2330.

[5] S.J. Allen, B. Koumanova, Decolourization of water/waste water using adsorption, J. Univ Chem Technol Metel. 40 (2003) 175-192.

[6] B.K. Nnadi, A. Goswami, M.K. Purkait, Adsorption characertsitics of brilliant green dye on kaolin, J. Hazard. Mat. 16(1) (2009) 387.

[7] M.A.M. Salleh, D.K. Mahmoud, W.A. Karim, A. Idris, Cationic and anionic dye adsorption by agricultural solid wastes: A comprehensive review, Desalination. 280 (2011)1 -13.

[8] C. Parvathi, T. Maruthavanan, S. Sivamani, C. Prakash, Biosorption studies for the removal of malachite green from its aqueous solution by activated carbon prepared from cassava peel, E-Journal of Chemistry. 8(1) (2011) 61-66.

[9] E. Forgacs, T. Cserhati, G. Oros, Removal of synthetic dyes from waste water: A review, J. Env. Intern. 30 (2004) 954-959.

[10] G. Crini, Non-conventional low-cost adsorbents for dye removal: A review, J. Bioreso. Technol. 97 (2006) 1062-1070.

[11] R. Jyoti, K. Shakti, (2013) A comparative study of adsorption behavior of a dye using agro wastes as adsorbents, J. Env. Sci. Toxico. And Food Technol. 4(5) (2013) 91-95.

[12] L.S. Tan, K. Jain, C.A. Rozaini, Adsorption of textile dye from aqueous solution on pretreated mangrove bark, an agricultural waste: Equilibrium and kinetic studies, J. App. Sci. Environ. Sani. 5(3) (2010) 266-276.

[13] A. Mokhtar et al., Removal of dyes from colored textile wastewater by orange peel adsorbent: Equilibrium and kinetic studies, Journal of Colloids and Interfacial Science. 288(2) (2005) 371-376.

[14] O. Dursun, D. Gulbeyi, O. Ahmet, Methylene blue adsorption from aqueous solution by dehydrated peanut hull, Journal of Hazardous Materials. 144(1) (2007) 171-179.

[15] C. Umpuch, B. Jutarat, (2013) Adsorption of organic dyes from aqueous solution by surfactant modified corn straw, Inter. J. Chem. Eng. Applications, 4(3) (2013) $134-139$.

[16] S.T. Akar, A.S. Ozcan, T. Akar, A. Ozcan, Z. Kaynak, Biosorption of a reactive textile dye from aqueous solutions utilizing an agro-waste, Desalination, 247 (2009) 757-761.

[17] S.S. Tahir, N. Rauf, Removal of a cationic dye from aqueous solution by adsorption onto bentonite clay, Chemos. 63 (2006) 1842-1848.

[18] R. Malik,D.S. Rametke, S.R. Wate, Adsorption of malachite green on groundnut shell waste based powdered activated carbon. J. Was. Manag. 27 (2006) $1-8$.

[19] C.K. Enenebeaku, N.J. Okorocha, C.O. Akalezi. Adsorptive Removal of Methylene Blue from Aqueous Solution Using Agricultural Waste: Equilibrium, Kinetic and Thermodynamic Studies. American Journal of Chemistry and Materials Science, 2(3) (2015) 14-25. 
[20] N. J. Okorocha, E. P. Nwojo, I. O. Achinihu, M.O. Chijioke-Okere, B.N. Anukam, \& C. E. Omaliko. Adsorption of selected heavy metals using agricultural waste: Equilibrium, kinetic and thermodynamic studies. American Journal of Engineering Research (AJER), 8(12) (2019) 71-87.

[21] R. Malik, D.S. Ramteke, \& S.R. Wate. Adsorption of malachite green on groundnut shell

[22] waste based powdered activated carbon. Waste Manag., 27 (2007) 1129-1138.

[23] W.C. Wanyonyi, J.M. Onyari, \& P.M. Shiundu. Adsorption of congo red dye from aqueous solutions using roots of eichhornia crassipes: Kinetic and equilibrium studies. Energy Procedia, 50 (2014) $862-869$.

[24] C.K. Enenebeaku, N.J. Okorocha, E.E. Uchechi, B.I. Onyeachu, Adsorption of Methylene Blue Dye onto Bush Cane Bark Powder, International Letters of Chemistry, Physics and Astronomy (ILCPA), 76 (2017) 12-26.

[25] P.S. Kumar, M. Palaniyappan, M. Priyadharshini, A.M. Vigensh, A. Thonjiappan, P.A.F. Sebastina, R.A. Tanvir, R. Srinath, Adsorption of basic dye onto raw and surface-modified agricultural waste, Env. Progress and Sustainable Energy, 33(1), (2013) 87 - 98.

[26] T. Santhi, S. Manonmani, Removal of Methylene blue from aqueous solution by bioadsorption onto Ricinus communis epicarp activated carbon, Chemical Engineering Research Bulletin, 13(1) (2009) 1-5.

[27] S.A. Dhahir et al., Adsorption of malachite green dye from aqueous solution onto Iraqi raw Al-Hussainiyat clay, Eur. Chem. Bull. 2(11), (2013) 866-872.

[28] A. El-Maghraby, H.A. El - Deeb, (2011). Removal of a basic dye from aqueous solution by adsorption using rice hulls, Global NEST. J., 13(1), (2011) 90 - 98.

[29] A. Ezgi, B. Mufit, Y. Mustafa, Removal efficiency of a calyx [4] arene-based polymer for water-soluble carcinogenic direct azo dyes and aromatic amines. Journal of Hazardous Materials, 162 (2008) 960-966.

[30] V. Dulman, S.M. Cucu-Man, Sorption of some textile dyes by beech wood sawdust, Journal of Hazardous Materials, 162 (2009) 1457-1464.

[31] M. Dogan, H. Abak, M. Alkan, Adsorption of methylene blue onto hazelnut shell: Kinetics, mechanism and activation parameters, Journal of Hazardous Materials, 164 (2009) 172-181.

[32] N.J. Okorocha, C.K. Enenebeaku, M.O. Chijioke-Okere, C.E. Ohaegbulam, C.E. Ogukwe, Adsorptive removal of crystal violet using agricultural waste: Equilibrium, kinetic and thermodynamic studies, American Journal of Engineering Research (AJER), 8(9), (2019) 3851.

[33] N.J. Okorocha, J.O. Okoji, C. Osuji. Adsorption of basic and acidic dyes onto agricultural wastes, international letters of chemistry, Physics and Astronomy (ILCPA), 70 (2016) 12-26.

[34] S. Chowdhury, R. Mishra, P. Saha. Adsorption thermodynamics, kinetics and isosteric heat of adsorption of malachite green onto chemically modified rice husk. Dio: 10.1016/ J.Desal.(2010).07.047

[35] S. Chowdhury, P. Saha. Sea shell powder as new adsorbent to remove basic green4 (malachite green) from aqueous solutions: Equilibrium, kinetic and thermodynamic studies, Chemical Engineering Journal, 164 (2010) 168-177. 